\title{
Catching Students in an Inverted Classroom Environment
}

\author{
Anja Pfennig* \\ HTW Berlin, University of Applied Sciences Berlin, Wilhelminenhofstraße 75A, 12459 Berlin, Germany. \\ * Corresponding author. Tel.: 004930 50194231; email: anja.pfennig@htw-berlin.de \\ Manuscript submitted August 24, 2016; accepted March 10, 2017. \\ doi: 10.17706/ijeeee.2017.7.2.85-90
}

\begin{abstract}
Flipping or Inverting the classroom as a method in an introductory material science course asks students to study the science of engineering materials on their own. In class we take time to discuss questions and solve problems or work on hands-on lectures or exercises in class. In blended-learning scenarios students use different materials to study and understand the science in theory and then the classroom lectures offer the opportunity for students to comprehend the principle of different aspects in material science and apply their knowledge. A high number and variety of teaching materials aims at different learning skills of the students and meets the diversity of a first year class. Therefore teaching materials and micro-module lectures to individually chose, combine and study from a distance are provided in a moodle based course. To assess the learning progress prior to each class peer response is used. Evening tests after each inverted classroom session, self-testing along with exercises and worked solutions allow students to control their learning progress. The inverted classroom approach may be applied to a choice of themes taught the first semester and both students success along with the fun of learning and teaching throughout the first year were increased.
\end{abstract}

Key words: Inverted classroom, moodle, teaching material, introductory course.

\section{Introduction}

Starting in winter semester 2014/15 the first semester material science has to be passed as a course, but the grades are not included into the bachelor`s degree for mechanical and automotive engineering at HTW Berlin [1], [2]. Peer response [3] and "nverting the classroom" [4], [5] seemed to be the appropriate medium to gain student's attention, motivate them right from the start to continuously study and acquire good exam results assuring each to easily pass the graded exam the second semester.

The flipped classroom constitutes a role change for instructors, who give up their front-of-the-class position in favor of a more collaborative and cooperative contribution to the teaching process. Activities can be student-led, and communication among students can become the determining dynamic of a session devoted to learning through hands-on work [5]. Moreover students got to know each other much better, were fond of the course, found materials science entertaining and had personal success when understanding complicated contents. The quality of the work comprised in class was successfully high with students working seriously on their tasks resulting in better grades than the previous semester. Lectures are the appropriate platform to exercise, ask questions and discuss matters with student colleagues and lecturers. Parts of this work has been presented at HEAd 16 [2] and I would now like to give a follow up.

\section{Lecture Concept of Materials Science in Mechanical Engineering}


During 2015 to 2016 we got very good results when students were to prepare lectures, watch introductory films [2] and do homework exercises prior to the lecture in presence. An important issue of the concept is, that the students were able to study individually, self-directed, location-independent, asynchronously and according to their individual tempo. In class we had time to discuss problems, work on exercises and engineering related problems, share difficulties and thoughts with classmates and especially experience that the background information (self-taught at home) delivered a great deal of understanding of the correlation between materials properties and microstructure. Among others study materials are:

- Micro module lectures intermixed with problems and worked solutions

- Worksheets and worked solutions

- Lecture videos (actual semester) and teaching videos [2], [6]

- (interactive) Mindmaps

- Memory sheets to memorize most important aspects

- Online tests (for self-testing and assessing through lecturer)

The material science course for first year mechanical engineering students at HTW Berlin is taught via the "design-led" teaching approach [7], (Fig. 1). In contrast to the conventional "science-led" teaching approach the design led approach starts with the needs of the design and then explains why and how properties can be influenced and changed.

Science-driven approach

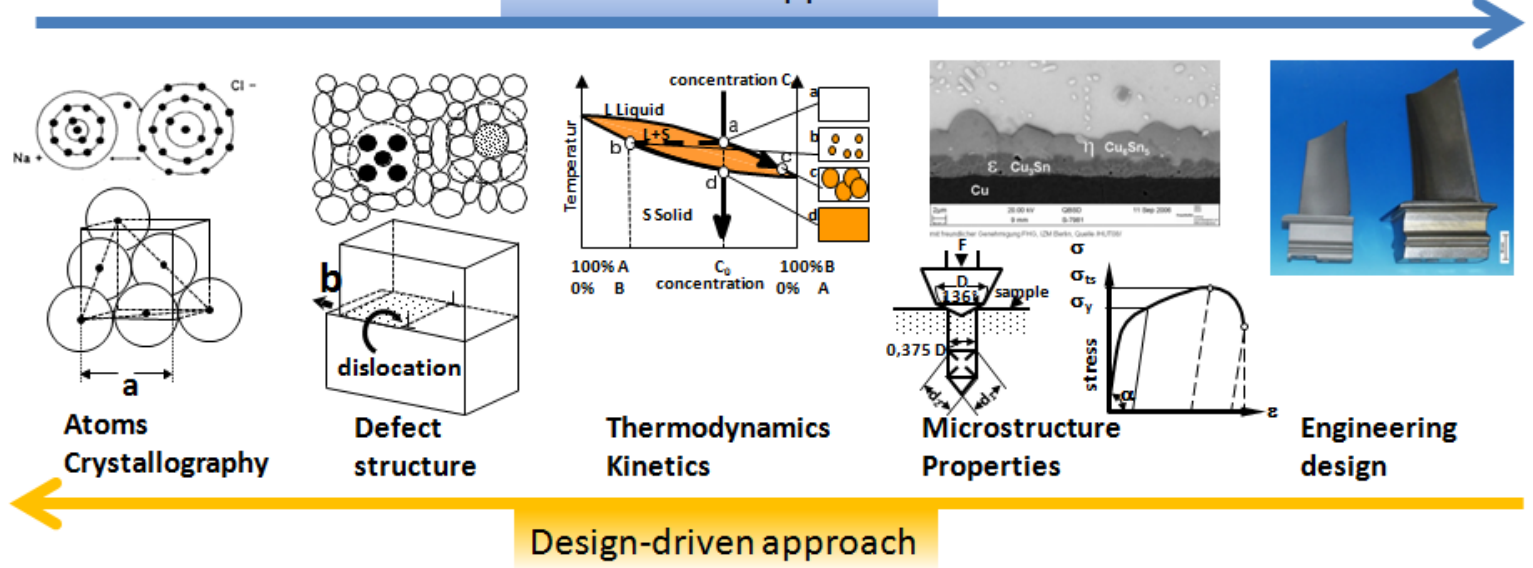

Fig. 1. "Science-led-approach" and "design-led-approach", adopted from [7].

The following themes are covered during the first year of material science and available via the content management system "moodle".

First semester (short overview only)

- Material selection

- Stiffness and elasticity

- Strength and ductility

- Materials testing

- Phase diagrams

- Iron and carbon
Second Semester (short overview only)

- Corrosion

- Creep and diffusion

- Fatigue

- Light weight alloys: Aluminum, Magnesium, Titanium

- Shape Memory Alloys (in progress)

- Various themes chosen, worked and presented by students

Therefore according to the peer-to-peer approach [2] various lecture videos have been produced to serve better understanding of scientific backgrounds and support the students` learning output during the self 
study periods.

- Introduction to fibre reinforced polymers: https://www.youtube.com/playlist?list=PLUOlZMSZYz5y8XYE1S09HIH60tSxlUERe

- Introduction to material science laboratory work: https://www.youtube.com/playlist?list=PLUOlZMSZYz5wHGs9vEu-5DWqmsktUvtx7

- Introduction to polymers: https://www.youtube.com/playlist?list=PLUOlZMSZYz5wUlfwge0VTxKokobD_00K7

- Strength and plasticity: https://www.youtube.com/playlist?list=PLUOlZMSZYz5wm7m-ahbD8r4dCjDU498mV

- Defects in crystals: https://www.youtube.com/playlist?list=PLUOlZMSZYz5wlO3gea5jLFhxgAr3IiOja

- Korrosion: https://www.youtube.com/playlist?list=PLUOlZMSZYz5z_aPBqnCjjr50XqF997-dJ In progress: diffusion, engineering materials, stress-strain-diagram

\section{Practice Examples}

\subsection{First Lecture Day: Materials Families and Groups}

Prior to the first contact class each student was asked to bring one favorite material and introduce themselves and their component focusing on main mechanical properties. They were then asked to put the component on a certain space on the floor assigning special mechanical properties to these. For the first students this was easy, following students had to decide whether to group materials or assign a new position. The "think-pair-share" method [1], [2], [6] was then used to discuss the properties and the grouping and decide on one solution. As a side effect students got to know each other. The result was related to a material family model and related also to their characteristic microstructure. Microstructures are essential to get a fundamental understanding on materials' properties. Therefore easy lectures introducing engineering materials, components and their microstructures were given as homework assignment. Along with the microstructures the most important properties had to be summarized into given templates, building basically on high school knowledge. The class was given several typical viewgraphs of microstructures and had to match these with the components and describe what they thought was characteristic about the microstructure. During the entire material science course it was easier for the lecturer to talk about materials families and microstructure in any context, because students remembered and combined quickly.

\subsection{Hardening Mechanisms and What to Do with Unprepared Students}

The scientific background of the four hardening mechanisms in materials science generating changes in microstructure in order to increase the strength of materials was given as homework (moodle-lecture, memory sheets and voluntarily reading of a simple and short scientific research paper). Along with the online lectures questions and tests had to be taken and one specific technical term had to be explained in a topic related glossary. This was commented and corrected by the lecturer in the week of the homework assignment.

In class the open-source software "invote" [8] was used for peer reviewing [1], giving the lecturer an overview of the student's knowledge. This also helped students to assess their learning progress. Questions were answered and important issues individually explained. Then students were divided into groups with 4-6 students each. A special template (Fig. 2) had to be used to summarize one of the 4 mechanisms, including: microstructural changes and impact on mechanical properties.

To make sure all students had nearly the same level of scientific knowledge; students who were not able to work properly at home got different, more basic assignments and were then later intermixed with groups 
doing the hands on lessons on hardening mechanisms. All students were then asked to prepare their results and briefly present these in front of the class as well as hand in a one page precise summary. These summaries were reviewed by the class and lecturer and uploaded in moodle to be available to all students. Then 2 engineering problems focusing on increasing strength in steels were solved in groups of two students each. Testing the following week proved good understanding and delivered better results than obtained the previous semester. Average outcome was 4.06 points out of 5 with 30 questions to be answered in 45 minutes (Fig. 3).
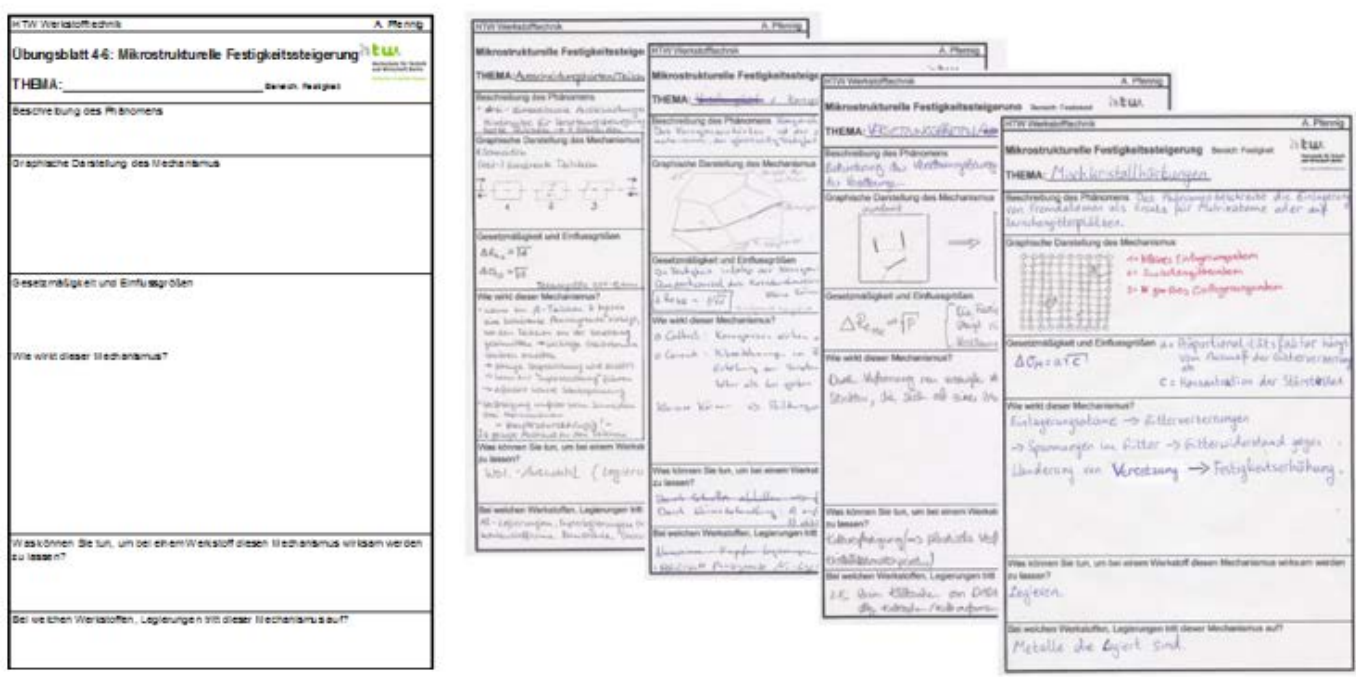

Fig. 2. Templates used to guarantee accumulation of scientific background and help students to prepare for evening exams.
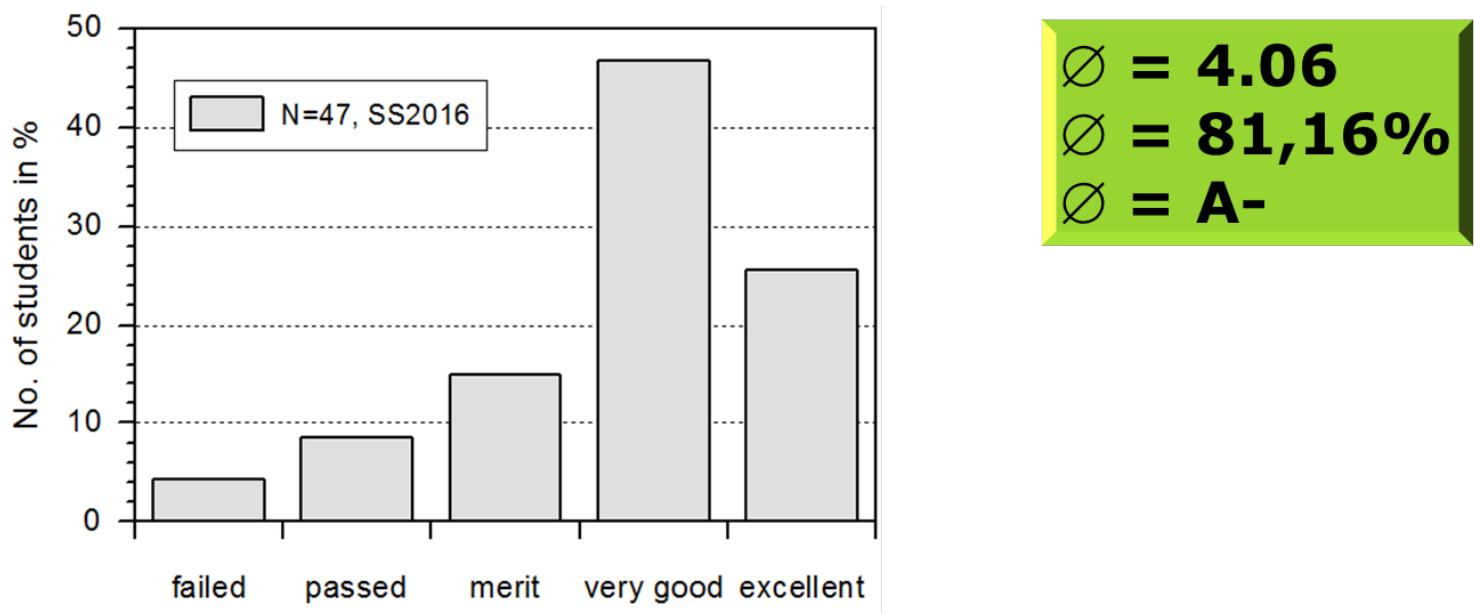

Fig. 3. Results of compulsory online exam on hardening mechanisms in SS2016.

\section{Evaluation}

First measures indicate better grades and higher learning output overall. I agree with many other authors who state that giving students more responsibility for their learning progress is effective in getting students to engage in critical thinking [9], [10]; thus, producing deeper learning outcomes [1], [9], [11]. Lecturers had a better overview on the progress of the class and were able to help and give advice where necessary. The atmosphere in class was very pleasant and students seemed to have fun experiencing and finding their newly gained knowledge useful to find solutions to material science problems. Especially working with 
small groups and teaching individually is of great advantage because not only explanations meet the students' needs, but they feel addressed more personally and were therefore more motivated to work on assignments. Lecturers will teach lively students eager to dispose their knowledge and learn more of the details, share their knowledge helping others and contributing to solving problems. Starting with 41 (second semester) and 55 in WS2015/16 and 46 in SS2016 students (first semester) approximately 26-32 and $42 / 35$ were present until the end of the semester, who were still very eager to work and gain knowledge. Those present stated that although it is a lot to learn and a very theoretical subject the different learning materials enhanced their learning progress and joy of studying and led to a more homogeneous study atmosphere during class.

The preparation time of the lectures and the teaching material is outrageous and does not compare to conventional lectures. Students who are not willing to study at home will be lost in the long run, first because of lack of background knowledge, second because they are not able to contribute to group or class work or work on assignments independently. Therefore it is always necessary to prepare teaching and learning material involving these students during the lecture and to help them catch up missing information. This also results in more work ahead of the lecture and may demotivate those students that are well prepared.

\section{Conclusion and Future Work}

The inverted classroom technique was introduced to first year mechanical engineering students enrolled in a material science course. Therefore micro moodle-based online lectures, films, screen casts, lecture slides and various teaching material were provided along with a distinct assignment for one week and regular graded tests and assignments. In class the students focused on discussing scientific backgrounds and solving hands-on engineering problems in groups of 2 to 4 students. Inverting the classroom involved students to take over the responsibility for their own learning process and the method was assessed as beneficial in terms of student grades, concentration and attentiveness as well as joy of studying. Still, evaluation over a long period of time has to prove in future, if this concept will enhance students` material science skills and grades in general.

\section{Acknowledgements}

The author would like to thank Astrid Böge and Paul Hadwiger for worthy discussions and advice on lecture concepts. Part of the work was funded by „excelLuS“ HTW-Berlin: "Studieren an der HTW Berlin exzellente Lehre und hervorragender Service", Förderprogramm "Bund-Länder-Programm für bessere Studienbedingungen und mehr Qualität in der Lehre" des Bundesministeriums für Bildung und Forschung (BMBF) mit Förderkennzeichen: 01 PL 11034 und Förderzeitraum vom 01.11.2011 - 30.06.2016.

\section{References}

[1] BerlHG; § 33, Absatz 2 und im Speziellen auf der Rahmenstudien- und -prüfungsordnung für Bachelorund Masterstudiengänge - RStPO - Ba/Ma; § 14, Absatz 7 der HTW.

[2] Pfennig, A. (2016). Inverting the classroom in an introductory material science course. Proceedings of $2^{\text {nd }}$ International Conference on Higher Education Advances, Procedia - Social and Behavioral Sciences Vol. 228 (pp. 32-38).

[3] Simon, B., Kohanfars, M., Lee, J., Tamayo, K, \& Cutts, Q. (2010). Experience report: Peer instruction in introductory computing. Proceedings of the 41st ACM Technical Symposium on Computer Science Education (pp. 341-345).

[4] Brame, C. J. (2015). Flipping the classroom. Retrieved from the website: 
http://cft.vanderbilt.edu/files/Flipping-the-classroom.pdf, call: 09/2015

[5] Educause. (2016). Educause learning initiative. Retrieved from the website: https://net.educause.edu/ir/library/pdf/eli7081.pdf, call: 01/2016

[6] Pfennig, A., \& Hadwiger, P. (2016). Peer-to-peer lecture films - a successful study concept for a first year laboratory material science course. Proceedings of $2^{\text {nd }}$ International Conference on Higher Education Advances, Procedia - Social and Behavioral Sciences Vol. 228 (pp. 24-31).

[7] Ashby, M., Shercliff, H., \& Cebon, D. (2013). Materials Engineering, Science, Processing and Design.

[8] Invote. (2016). Retrieved from the website: http://invote.de/, call 01/2016

[9] Colorado State University. (2015). Using peer teaching in the classroom. Retrieved from the website: http://teaching.colostate.edu/tips/tip.cfm?tipid=180

[10] Lord, T. (2012). 101 reasons for using cooperative learning in biology teaching. The American Biology Teacher, 63(1), 30-38.

[11] Goto, K., \& Schneider, J. (2010). Learning through teaching: Challenges and opportunities in facilitating student learning in food science and nutrition by using the interteaching approach. Journal of Food Science Education, 9(1), 31-35.

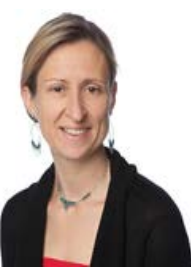

Anja Pfennig was born in Büdelsdorf, Germany in April 1970. She studied minerology at the Rheinische Friedrich Wilhelms University Bonn, Germany, where she graduated in 1997. Her Ph.D. in the field of ceramic moulds for liquid metal casting was earned in 2001 from the Friedrich Alexander University of Erlangen, Germany. She then worked for siemens energy in charge of ceramic shields and transferred to Berlin in 2008 where she currently teaches material science for engineering students at the Applied University Berlin, HTW. A. Pfennig research interest and expertise is in the field of corrosion fatigue of materials at high temperature and high pressure simulating geothermal environments. Her interest in teaching lies in the field of new teaching methods and e-learning to enhance students learning output and enabling them to cope in future positions. 